\title{
Apuntes acerca de la responsabilidad solidaria en el Impuesto a la Renta de la sociedad emisora en la enajenación directa de acciones directas realizada entre partes no vinculadas
}

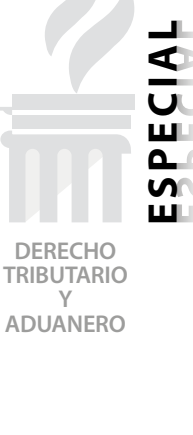

Sergio Vega-León Cabrera

Abogado por la Universidad Peruana de Ciencias Aplicadas. Máster en Derecho por la Universidad de Nueva York.

SUMARIO:

I. Introducción.

II. Alcances del Artículo 68 de la LIR.

III. Origen y justificación del Artículo 68 de la LIR.

IV. Precedentes administrativos aplicables al caso del Artículo 68 de la LIR.

1. Informe 173-2013-SUNAT/4B0000.

2. Jurisprudencia del Tribunal Fiscal.

V. Reflexiones finales. 


\section{RESUMEN:}

A través del presente ensayo, el autor comenta la problemática derivada de la responsabilidad solidaria que, en determinadas circunstancias, adquiere la sociedad emisora de acciones en el marco de una transferencia de acciones. Para tales efectos, el autor aborda los alcances del artículo 68 de la Ley del Impuesto a la Renta, así como sus orígenes y los precedentes más relevantes, para posteriormente realizar unas breves reflexiones sobre esta temática.

Palabras clave: enajenación, impuesto a la renta, responsabilidad solidaria, transferencia de acciones, deuda tributaria.

\footnotetext{
ABSTRACT:

Through this essay, the author comments on the problems derived from the several liability that, under certain circumstances, the share issuing company acquires within the framework of a share transfer. For such purposes, the author addresses the scope of article 68 of the Income Tax Law, as well as its origins and the most relevant precedents, to later make brief reflections on this topic.

Keywords: alienation, income tax, several liability, transfer of shares, tax liability.
}

\section{INTRODUCCIÓN}

En el Perú, como regla general, la transferencia onerosa de acciones representativas del capital de una sociedad establecida en el país, sea cual fuere el domicilio de su titular, califica como una enajenación', cuyo resultado es susceptible de tributar con el Impuesto a la Renta a la ganancia de capital, el cual surge de comparar el valor de mercado de las acciones enajenadas, con su correspondiente costo para propósitos fiscales. $^{2}$

Pese a que el contribuyente del referido impuesto a la ganancia de capital sea el enajenan- te - transferente o vendedor- y pierda total vinculación con la compañía peruana cuyas acciones transfiere como producto de su enajenación, bajo determinados supuestos previstos en la legislación del Impuesto a la Renta la emisora de las referidas acciones será responsable solidaria del citado impuesto. Ello ocurre cuando el transferente es un sujeto no domiciliado en el Perú, siempre que antes de la enajenación hubiese estado vinculado a la sociedad emisora, a través del capital, la administración o el control. $^{3}$

En principio, carecería de sentido lógico que el emisor fuese responsable solidario de una deu-

1. De conformidad con el artículo 5 del Texto Único Ordenado de la Ley del Impuesto a la Renta - LIR, aproabado por Decreto Supremo N ${ }^{\circ}$ 179-2004-EF, "se entiende por enajenación la venta, permuta, cesión definitiva, expropiación, aporte a sociedades y, en general, todo acto de disposición por el que se transmita el dominio a título oneroso."

2. El presente artículo no aborda la problemática relacionada las enajenaciones indirectas de acciones reguladas en el inciso e) del artículo 10 de la LIR.

3. "Artículo 68.- En la enajenación directa e indirecta de acciones, participaciones o de cualquier otro valor o derecho representativo del patrimonio de una empresa a que se refiere el inciso h) del artículo 9 y los incisos e) y f) del artículo 10 de esta Ley, respectivamente, efectuada por sujetos no domiciliados, la persona jurídica domiciliada en el país emisora de dichos valores mobiliarios es responsable solidaria, cuando en cualquiera de los doce (12) meses anteriores a la enajenación, el sujeto no domiciliado enajenante se encuentre vinculado directa o indirectamente a la empresa domiciliada a través de su participación en el control, la administración o el capital. El reglamento señalará los supuestos en los que se configura la referida vinculación.

Tratándose de la enajenación indirecta de acciones o participaciones a que se refiere el inciso e) del artículo 10 de la Ley realizada por una persona jurídica no domiciliada en el país que tiene una sucursal o cualquier otro establecimiento permanente en el país que cuente con un patrimonio asignado, se considera a este último como responsable solidario.

(Continúa en siguiente página) 
da tributaria generada por su anterior propietario - el enajenante de las acciones-, pues en el caso de una compraventa dicho emisor no solo no es parte de la relación contractual; sino que, además, podría no haber tenido contacto con los recursos dinerarios provenientes de la transferencia -el precio- que haya percibido el vendedor o enajenante. Esta situación se agrava si el adquirente es una parte no relacionada al enajenante. Comercialmente, el escenario descrito es bastante común y corresponde a los casos de venta de acciones peruanas entre partes no vinculadas en donde el vendedor es un sujeto no domiciliado.

El presente trabajo tiene como propósito comentar la problemática derivada de la responsabilidad solidaria de la sociedad emisora de las acciones en el escenario de venta previamente indicado, para lo cual abordaremos, desde un punto de vista crítico, los alcances del artículo 68 de la Ley del Impuesto a la Renta - LIR, su origen y precedentes administrativos relevantes; así como algunas reflexiones finales a tomar en cuenta, considerando las zonas grises de la responsabilidad solidaria en cuestión que, a nuestro juicio, debería limitarse legislativa o jurisprudencialmente. ${ }^{4}$

\section{ALCANCES DEL ARTÍCULO 68 DE LA LIR}

Para fines de este trabajo, la parte pertinente del artículo 68 de la LIR que tomaremos en consideración es la siguiente:

"En la enajenación directa e indirecta de acciones, participaciones o de cualquier otro valor o derecho representativo del patrimonio de una empresa a que se refiere el inciso h) del artículo 9 y los incisos e) y f) del artículo 10 de esta Ley, respectivamente, efectuada por sujetos no domiciliados, la persona jurídica domiciliada en el país emisora de dichos valores mobiliarios es responsable solidaria, cuando en cualquiera de los doce (12) meses anteriores a la enajenación, el sujeto no domiciliado enajenante se encuentre vinculado directa o indirectamente a la empresa domiciliada a través de su participación en el control, la administración o el capital. El reglamento señalará los supuestos en los que se configura la referida vinculación.

(...)

No se atribuirá la responsabilidad solidaria cuando sea de aplicación la retención prevista en el inciso g) del artículo 71 de la Ley.

(...)."

Excluyendo las implicancias derivadas de la responsabilidad solidaria regulada en la citada norma para el caso de enajenaciones indirectas, que no son materia de este trabajo, de los referidos párrafos se desprende que, para las enajenaciones directas de acciones ${ }^{5}$, la persona

El responsable solidario señalado en el párrafo anterior debe proporcionar la información relacionada con las acciones o participaciones representativas del capital de la persona jurídica no domiciliada en el país cuyas acciones o participaciones se enajenan, en particular, la referida a los valores de mercado, porcentajes de participación, aumento o reducción de capital, emisión y colocación de acciones o participaciones, procesos de reorganización, valores patrimoniales y balances, conforme a lo que establezca el reglamento.

No se atribuirá la responsabilidad solidaria cuando sea de aplicación la retención prevista en el inciso g) del artículo 71 de la Ley.

La responsabilidad solidaria se mantendrá cuando la retención se efectúe por las instituciones de compensación y liquidación de valores o quienes ejerzan funciones similares."

4. Nótese que, en estricto, no es solo la venta la que podría gatillar la responsabilidad solidaria del emisor, pudiendo generarse a partir de reorganizaciones empresariales, como fusiones y escisiones, entre otras figuras societarias.

5. Conforme al inciso h) del artículo 9 de la LIR, "En general y cualquiera sea la nacionalidad o domicilio de las partes que intervengan en las operaciones y el lugar de celebración o cumplimiento de los contratos, se considera rentas de fuente peruana:

(...)

(Continúa en siguiente página) 
jurídica domiciliada emisora de las respectivas acciones será responsable solidaria del impuesto a la ganancia de capital que grava la transacción, cuando se cumplan, conjuntamente, las siguientes dos condiciones:

a) El vendedor sea un sujeto no domiciliado; $y$

b) En cualquiera de los doce meses anteriores a la enajenación, el vendedor esté vinculado al emisor de las acciones que se enajenan, vía control, administración o capital, según lo que indique el Reglamento de LIR. $^{6}$

En sentido contrario, si el vendedor es un sujeto domiciliado en el país, o si siendo no domiciliado no tuviese vinculación con la sociedad emisora de las acciones que se enajenan, no nacerá la responsabilidad solidaria respecto del impuesto a la ganancia de capital originado en la venta de las referidas acciones.

Nótese que, bajo una interpretación literal de la norma, si se verifican las dos condiciones antes descritas y el adquirente es un sujeto domiciliado en Perú, no se atribuirá responsabilidad solidaria al emisor únicamente si nos encontramos en el caso de una enajenación indirecta, mas no en el supuesto de una transferencia directa de acciones. Ello debido a que el inciso g) del ar- tículo 71 mencionado en el citado artículo 68 de la LIR califica exclusivamente como agente de retención a los sujetos domiciliados que paguen o acrediten rentas por la enajenación indirecta de acciones regulada en el inciso e) del artículo 10 de la citada ley; y no a aquellos que lo hagan en el caso del inciso h) del artículo 9, que regula a las rentas por enajenación directa. ${ }^{7}$

Consideramos que, injustificadamente, la situación previamente comentada genera desigualdad entre los adquirentes domiciliados de acciones vía enajenación indirecta y los adquirentes de acciones vía enajenación directa, pues en el primer caso dichos sujetos serían responsables solidarios en calidad de agentes de retención, liberándose al emisor como responsable solidario; mientras que en el segundo, podrían coexistir hasta dos tipos de responsabilidad solidaria: (i) la generada para la sociedad emisora en base a lo dispuesto por el artículo 68 de la LIR, y (ii) la que nace para el sujeto adquirente como agente de retención por el solo hecho de calificar como tal, de acuerdo con el inciso c) del artículo 71 de la LIR.

En efecto, conforme al numeral 2 del artículo 18 del Código Tributario ${ }^{8}$, son responsables solidarios con el contribuyente los siguientes:

"Los agentes de retención o percepción,

\footnotetext{
h) Las obtenidas por la enajenación, redención o rescate de acciones y participaciones representativas del capital, acciones de inversión, certificados, títulos, bonos y papeles comerciales, valores representativos de cédulas hipotecarias, obligaciones al portador u otros valores al portador y otros valores mobiliarios cuando las empresas, sociedades, Fondos de Inversión, Fondos Mutuos de Inversión en Valores o Patrimonios Fideicometidos que los hayan emitido estén constituidos o establecidos en el Perú.

Igualmente se consideran rentas de fuente peruana las obtenidas por la enajenación de los ADR's (American Depositary Receipts) y GDR's (Global Depositary Receipts) que tengan como subyacente acciones emitidas por empresas domiciliadas en el país."

(...)"
}

6. Reglamento de la LIR, aprobado por Decreto Supremo N 122-94-EF, cuyo artículo 39-F establece lo siguiente: "Artículo 39-F.- Responsabilidad solidaria

Para efectos de la aplicación de lo dispuesto en el artículo 68 de la Ley, existirá vinculación entre el sujeto no domiciliado enajenante y la persona jurídica domiciliada, cuando en cualquiera de los doce (12) meses anteriores a la fecha de enajenación se den alguno de los siguientes supuestos:

1. El sujeto no domiciliado posea más del diez por ciento (10\%) del capital de la persona jurídica domiciliada, directamente o por intermedio de un tercero.

2. El capital de la persona jurídica domiciliada y del sujeto no domiciliado pertenezca, en más del diez por ciento (10\%), a socios comunes a éstas.

3. La persona jurídica domiciliada y el sujeto no domiciliado cuenten con uno o más directores, gerentes, administra- 
cuando hubieren omitido la retención o percepción a que estaban obligados. Efectuada la retención o percepción el agente es el único responsable ante la Administración Tributaria."

A ello debemos agregar que, conforme al inciso c) del citado artículo 71 de la LIR, son también agentes de retención "Il]as personas o entidades que paguen o acrediten rentas de cualquier naturaleza a beneficiarios no domiciliados".

Evidentemente, no es razonable, necesario, ni conceptualmente acertado que coexistan dos tipos de responsabilidad solidaria sobre sujetos distintos - adquirente y emisor - en el caso de una enajenación directa, por lo que, en nuestra opinión, una correcta interpretación del artículo 68 de la LIR debiera conducir a limitar la responsabilidad de la entidad emisora únicamente para supuestos en los que el adquirente sea un sujeto no domiciliado. En ese sentido, la norma citada del Código Tributario debería prevalecer sobre el artículo 68 de la LIR. Creemos que esa falta de coherencia responde a un error legislativo que debería ser corregido a través de una norma con carácter de precisión, por razones de seguridad jurídica y para evitar contingencias en las fiscalizaciones que practique la Administración Tributaria.

\section{ORIGEN Y RAZÓN DE SER DEL ARTÍCULO 68 DE LA LIR}

Antes de que el artículo 68 de la LIR regulara la responsabilidad solidaria del ente emisor, ésta se encontraba establecida en el inciso i) del artículo 67 de dicha ley, incorporado por el Decreto Legislativo 945, publicado el 23 de diciembre del año 2003. Sin embargo, la redacción de esta norma era distinta, tal como se observa a continuación:

"Artículo 67.- Están obligados a pagar el impuesto con los recursos que administren o dispongan y a cumplir las demás obligaciones que, de acuerdo con las disposiciones de esta ley corresponden a los contribuyentes, las personas que a continuación se enumeran:

i) En la enajenación de valores mobiliarios efectuada por sujetos domiciliados o no domiciliados, la sociedad o empresa domiciliada en el país emisora de acciones, participaciones $u$ otros valores mobiliarios representativos de un derecho de participación en su capital, siempre que tales valores mobiliarios no se encuentren inscritos en alguna Bolsa de Valores del país.

\section{$(\ldots)^{\prime \prime}$}

dores u otros directivos comunes, que tengan poder de decisión en los acuerdos financieros, operativos y/o comerciales que se adopten.

4. El sujeto no domiciliado y la persona jurídica domiciliada consoliden Estados Financieros.

5. El sujeto no domiciliado ejerza influencia dominante en las decisiones de los órganos de administración de la persona jurídica domiciliada o viceversa.

Se entiende que se ejerce influencia dominante cuando, en la adopción del acuerdo, se ejerce o controla la mayoría absoluta de votos para la toma de decisiones en los órganos de administración de la persona jurídica domiciliada o sujeto no domiciliado.

La vinculación quedará configurada y regirá de acuerdo a las siguientes reglas:

a) En el caso de los numerales 1 al 4 cuando se verifique la causal. Configurada la vinculación, ésta regirá desde ese momento y mientras subsista dicha causal.

b) En el caso del numeral 5, desde la fecha de adopción del acuerdo hasta el cierre del ejercicio gravable siguiente".

7. En efecto, el inciso g) del artículo 71 de la LIR establece lo siguiente:

"Artículo 71.- Son agentes de retención:

g) Las personas domiciliadas en el país cuando paguen o acrediten rentas por la enajenación indirecta de acciones o participaciones representativas del capital de una persona jurídica domiciliada en el país de acuerdo a lo dispuesto en el inciso e) del artículo 10 de esta Ley."

8. Código Tributario, con Texto Único Ordenado aprobado por Decreto Supremo № 133-2013-EF. 
Como se observa, la citada norma difería del texto actual del artículo 68 de la LIR porque convertía en responsable solidario al emisor, sin importar si el enajenante era o no domiciliado; y, además, el encabezado del artículo 67 limitaba la responsabilidad a "los recursos que administren o dispongan", con lo cual, la sociedad emisora no tenía la obligación de cubrir con sus propios recursos el impuesto a la ganancia de capital del enajenante en calidad de responsable, limitación que no existe en el actual texto del artículo 68. Cabe precisar que la norma que reglamentó el derogado inciso i) del artículo 67 de la LIR, estableció que los "recursos que administren o disponen" las sociedades emisoras se conforman por los dividendos, cuentas por pagar y cualquier otro crédito a favor del enajenante. ${ }^{9}$

Nos queda claro que dicha norma establecía límites razonables a la responsabilidad solidaria del ente emisor, en comparación con la norma actual recogida en el artículo 68 de la LIR. ${ }^{10}$

Posteriormente, el inciso i) del artículo 67 de la LIR fue derogado por el Decreto Legislativo 979, publicado el 15 de marzo de 2007.

Acertadamente, la Exposición de Motivos del citado Decreto sustenta dicha derogación en lo siguiente:

“En la práctica, los sujetos a los que el inciso mencionado les asigna responsabilidad solidaria carecen de los mecanismos adecuados que les permitan controlar el cumplimiento de las obligaciones tributarias sustanciales y formales que nacen para el contribuyente por efecto de la enajenación de valores mobiliarios. No obstante, por efecto de la atribución de la responsabilidad solidaria, resultarian obligados a cubrir las obligaciones generadas en cabeza de un tercero.

\section{Mediante la modificación se elimina el inciso en cuestión.}

La modificación no compromete inversión alguna por parte del Estado, permitiendo otorgar mayor seguridad jurídica a las entidades emisoras de valores mobiliarios".11

Sin embargo, cuatro años después a raíz del caso Petrotech $^{12}$, las reglas tributarias en el Perú fueron modificadas nuevamente para extender el ámbito de aplicación del Impuesto a la Renta a los casos de enajenaciones indirectas de acciones cuyo subyacente principal se componga de activos peruanos.

9. Reglamento de la LIR:

"Artículo 39.- RESPONSABLES Y AGENTES DE RETENCION Y DE PERCEPCION DEL IMPUESTO

Los responsables y agentes de retención y de percepción del impuesto, se sujetarán a las siguientes normas:

(...)

h) Los recursos que administran o disponen las sociedades o empresas domiciliadas en el país, emisoras de acciones, participaciones y otros valores mobiliarios, a que se refiere el inciso i) del Artículo 67 de la Ley, están representados por el patrimonio de dichas sociedades o empresas, incluyendo los dividendos, cuentas por pagar y cualquier otro crédito a favor del enajenante sea éste domiciliado o no.

En caso que el enajenante sea un sujeto domiciliado en el país, la responsabilidad solidaria de la sociedad o empresa emisora de los valores mobiliarios, no podrá exceder del importe del impuesto que se habría generado en la operación de enajenación.

La renta neta del enajenante no domiciliado se determinará de conformidad con lo señalado en el inciso g) del Artículo 76 de la Ley."

Dicho inciso fue incorporado por el artículo 11 del Decreto Supremo $N^{\circ}$ 086-2004-EF, publicado el 4 de julio de 2004.

10. Aun en este caso, Mario Madau en su ponencia individual para las IX Jornadas Nacionales de Derecho Tributario - Los Sujetos Pasivos Responsables en Materia Tributaria, sobre el referido inciso i) del artículo 67 de la LIR, ha manifestado que "(...) Llama la atención que se haga recaer la responsabilidad en un sujeto que está totalmente ajeno a la operación que genera la renta gravada y por lo tanto a la obligación tributaria. En otras palabras, si bien 
La referida modificación se inició con la dación de la Ley 29663, publicada el 15 de febrero de 2011, la misma que, además, reintroduce el concepto de la responsabilidad solidaria para la sociedad peruana emisora, incorporando el texto del artículo 68 de la LIR cuyo contenido esencial perdura hasta la fecha, pero esta vez abarcando a enajenaciones directas e indirectas efectuadas por sujetos no domiciliados. Según la Exposición de Motivos de la Ley 29663, el sustento de dicha responsabilidad es el siguiente:

"(...) Al respecto, se debe tener en cuenta que la figura de la responsabilidad solidaria en materia tributaria se sustenta, entre otras razones, en la disminución en los costos para el Estado en la recaudación y cobro de los tributos (...); en una mayor eficiencia en la administración y fiscalización de los tributos; en la necesidad de asegurar la regularidad de la recaudación de tributos (...)

Ahora bien, no obstante las razones que justifican la responsabilidad solidaria, los sujetos que son calificados como responsables solidarios por la Ley, deben encontrarse en algún grado de relación con el deudor original, a efecto de que sea razonable imputarles legalmente dicha calificación. Esta situación se evidencia en el Proyecto, toda vez que se ha establecido que la empresa emisora de los valores mobiliarios enajenados directa o indirectamente, será responsable solidario solo si está vinculada con el sujeto no domiciliado enajenante, a través de su participación en el control, la administración o el capital."13

Nos preguntamos por qué el hecho de que un accionista esté vinculado a la sociedad emisora de acciones antes - no después - de su venta a un tercero tendría que convertir a dicha sociedad en responsable solidaria, pues además de no ser parte de la relación contractual que da origen a la venta, precisamente, con la enajenación, la vinculación podría desaparecer. En efecto, en general, con ventas de control, el accionista original deja de tener relación con la sociedad emisora y el adquirente de las acciones es el nuevo vinculado a aquella. Adicionalmente, si el emisor en ningún momento está en posición de tomar contacto con los recursos provenientes de la transacción -el precio-, no tendría sentido lógico que deba responder por la tributación de la ganancia de capital correspondiente.

En este punto, consideramos relevante comentar que el Tribunal Constitucional perua-

no cabe duda que la finalidad es asegurar la recaudación, el criterio de selección utilizado para elegir al responsable no se relaciona con el incumplimiento de la obligación, ni con la adquisición de bienes que generaron las situaciones gravadas." Mario A. Madau Martínez, "Reflexiones sobre el tratamiento de la responsabilidad solidaria y sustitución tributarias en el ordenamiento tributario peruano" en IX Jornadas Nacionales de Derecho Tributario, relator principal Luis Hernández Berenguel (Lima: IPDT, 2006).

11. Exposición de Motivos del Decreto Legislativo 979, página 12.

12. "En 2009, Ecopetrol Colombia y Korea National Oil Corp adquirieron una empresa con sede en Houston (Offshore International Group Inc.), cuyo principal activo era Petrotech Peruana (titular de la licencia), empresa constituida y residente en Perú y tercer productor de petróleo de dicho país, por aproximadamente USD 900 millones, de Petrotech International, empresa constituida en Delaware. Dado que, en ese momento, la ley del impuesto sobre la renta de Perú no incluía una disposición específica sobre la tributación de las ventas indirectas transnacionales, la transacción quedó exenta de impuestos en ese país. Según las estimaciones, los posibles ingresos fiscales no percibidos por Perú fueron de USD 482 millones. Petrotech International, residente de los Estados Unidos, pagaría en este último país los impuestos correspondientes a las ganancias de capital." Plataforma de Colaboración en materia Tributaria, Borrador de Consulta: Tributación de las transferencias indirectas transnacionales - Una guía práctica (2017), https://www.oecd.org/tax/ discussion-draft-toolkit-taxation-of-offshore-indirect-transfers-ESP.pdf.

13. Proyecto de Ley $\mathrm{N}^{\circ}$ 3092/2008-PE, páginas 13 y 14 . 
no, máximo intérprete de la Constitución y de la ley, en reiteradas sentencias ha delineado el concepto de "responsabilidad solidaria" en materia tributaria, según los siguientes criterios:

"8. El responsable solidario es aquel sujeto que sin tener la condición de contribuyente (es decir, sin haber realizado el hecho imponible) debe cumplir con la prestación tributaria atribuida a éste por un imperativo legal si su cumplimiento es requerido por el acreedor tributario. Esta responsabilidad surge en razón de ciertos factores de conexión con el contribuyente o como un mecanismo sancionatorio." ${ }^{14}$

\begin{abstract}
"27. Conforme a la lógica descrita y si bien se pueden crear responsabilidades solidarias, ellas se condicionan a dos supuestos:

(i) Conexión con el contribuyente (...)

(ii) Mecanismos sancionatorios (...)

En definitiva, se advierte que no existe un factor de conexión directo y proporcional que determine la responsabilidad solidaria por parte de las empresas supervisoras". ${ }^{15}$
\end{abstract}

A la luz de dichos pronunciamientos, tenemos que en un caso como el del artículo 68 de la
LIR, dado que no nos encontramos ante un mecanismo sancionatorio, la responsabilidad solidaria del ente emisor se fundamenta en la conexión con el contribuyente - el vendedor o enajenante-, pero esta conexión debe ser directa y proporcional, lo que a nuestro juicio en el caso analizado presenta ciertas deficiencias, debido a que:

a) La sociedad emisora no es parte de la relación contractual -comprador-vendedor- que da origen al nacimiento de la obligación tributaria;

b) El vendedor puede perder la conexión elegida por el legislador como criterio de atribución de responsabilidad solidaria vinculación a través del capital, la administración o el control- al momento de transferir sus acciones a un tercero; $y$

c) Dada la redacción actual de la norma, se podría interpretar que la deuda tributaria por el impuesto a la ganancia de capital derivada de dicha transferencia podría ser exigida, total o parcialmente, al ente emisor $y$, en este escenario, dicho sujeto tendría que responder con sus propios recursos, sin límite, ante la falta de parámetros

14. Considerando 8 de la Sentencia del Tribunal Constitucional recaída en el Expediente $\mathrm{N}^{\circ} 0002-2006-\mathrm{Pl}$, de fecha 16 de mayo de 2007.

15. Considerando 27 de la Sentencia del Tribunal Constitucional recaída en el Expediente № 2226-2007-PA, de fecha 26 de noviembre de 2007.

16. Sobre este punto volveremos en la Sección III del presente trabajo, al momento de analizar los precedentes administrativos existentes sobre la materia.

17. A manera de ejemplo, cabe citar un extracto de los considerandos de la Sentencia del Tribunal Constitucional recaída en el Expediente 06089-2006-PA de fecha 17 de abril de 2007:

"11. El Estado Social y Democrático de Derecho se configura sobre la base de dos aspectos básicos: a) La exigencia de condiciones materiales para alcanzar sus presupuestos, lo que exige una relación directa con las posibilidades reales y objetivas del Estado y con una participación activa de los ciudadanos en el quehacer estatal; y b) La identificación del Estado con los fines de su contenido social, de forma que pueda evaluar, con criterio prudente, tanto los contextos que justifiquen su accionar como su abstención, evitando tomarse en obstáculos para su desarrollo social.

12. Tales premisas son trasladables también al análisis de las controversias de carácter tributario, en cuyo caso la evaluación del fenómeno tributario implicará necesariamente que sea entendido a partir de la evolución de las relaciones Estado-Sociedad en materia económica. Así, si las transformaciones del Estado han conllevado, a su vez, la transformación de los roles sujeto privado-sujeto público e, igualmente, han determinado una mayor asunción de deberes por parte de los ciudadanos, resulta entendible que el fenómeno tributario, para mejor atender los cambios en las necesidades sociales, también extienda sus alcances más allá de la mera obligación sustantiva al pago, e 
regulados como los que se encontraban en el derogado inciso i) del artículo 67 de la LIR y en su norma reglamentaria. Ello no nos parece proporcional ni razonable, y solo se justificaría en la finalidad recaudatoria. ${ }^{16}$

Sin perjuicio de lo indicado en el párrafo precedente, debemos indicar que el Tribunal Constitucional en reiterados pronunciamientos ha delineado el alcance del denominado deber de colaboración de los administrados, el cual a criterio de dicho órgano justificaría la existencia de ciertas obligaciones administrativas, así como el establecimiento de responsabilidades solidarias de terceros vinculados al contribuyente por algún nexo económico y jurídico. ${ }^{17} \mathrm{~A}$ título ejemplificativo, cabe citar el Considerando 12 de la Sentencia del Tribunal Constitucional recaída en el Expediente $\mathrm{N}^{\circ}$ 06089-2006PA/TC de fecha 17 de abril de 2007:

"12 (...) Así, si las transformaciones del Estado han conllevado, a su vez, la transformación de los roles sujeto privado-sujeto público e, igualmente, han determinado una mayor asunción de deberes por parte de los ciuda- danos, resulta entendible que el fenómeno tributario, para mejor atender los cambios en las necesidades sociales, también extienda sus alcances más allá de la mera obligación sustantiva al pago, e incorpore otras obligaciones sucedáneas, tales como obligaciones de declaración o autoliquidación de tributos, de información en la fiscalización, la responsabilidad solidaria de terceros vinculados al contribuyente por algún nexo económico o jurídico, e, incluso, deberes de colaboración con la Administración en la lucha contra la informalidad y la evasión fiscal."

Por otro lado, tampoco tiene lógica que las normas que incluyeron a las enajenaciones indirectas como transacciones potencialmente sujetas a imposición en el Perú sean las que establezcan supuestos de responsabilidad solidaria para el caso de las enajenaciones directas de acciones que desde hace ya varios años estaban gravadas con el Impuesto a la Renta sobre la correspondiente ganancia de capital. La razonabilidad de establecer a un responsable en las ventas indirectas radica, precisamente, en el carácter indirecto de la transacción, pues es más difícil para el Fisco peruano identificar

incorpore otras obligaciones sucedáneas, tales como obligaciones de declaración o autoliquidación de tributos, de información en la fiscalización, la responsabilidad solidaria de terceros vinculados al contribuyente por algún nexo económico o jurídico, e, incluso, deberes de colaboración con la Administración en la lucha contra la informalidad y la evasión fiscal.

13. De ello puede afirmarse que siendo la función principal del tributo la recaudadora - entendida no como fin en símismo sino antes bien como medio para financiar necesidades sociales-, pueda admitirse que en circunstancias excepcionales y justificadas para el logro de otras finalidades constitucionales, esta figura sea utilizada con un fin extrafiscal o ajeno a la mera recaudación, cuestión que, indiscutiblemente, no debe ser óbice para quedar exenta de la observancia de los principios constitucionales que rigen la potestad tributaria.

14. Y es que la búsqueda de una sociedad más equitativa, propia del Estado Social y Democrático de Derecho, se logra justamente a través de diversos mecanismos, entre los cuales la tributación juega un rol preponderante y esencial, pues mediante ella cada ciudadano, respondiendo a su capacidad contributiva, apolia parte de su riqueza para su redistribución en mejores servicios y cobertura de necesidades estatales. De ahí q1 1e, quienes ostentan la potestad tributaria, no solo deban exhortar al ciudadano a contribuir con el sostenimiento de los gastos públicos, sin distinción ni privilegios; sino, al mismo tiempo, deban fiscalizar, combatir y sancionar las practicas de evasión tributaria, cuyos efectos nocivos para el fisco se tornan contraproducentes en igual medida para todos los ciudadanos del Estado Peruano. (...)

16. Consecuentemente ante la cuestión de si la tributación puede utilizarse para fines cuyo objetivo directo no sea el exclusivamente recaudador, sino la lucha contra la evasión iscal, la respuesta prima facie no puede ser sino afirmativa; puesto que, si bien la creación de un régimen determinado se justifica en la necesidad de frenar la informalidad y la evasión tributaria, resulta evidente que su fin ulterior será la mejora de los niveles de recaudación, evitando que el peso tributario recaiga injustamente sobre quienes sí cumplen sus obligaciones fiscales." 
al contribuyente y cobrarle el tributo, al ser éste el propietario no domiciliado de una entidad también no domiciliada cuyas acciones se transfieren, siendo que esta última entidad es la titular de las acciones peruanas, directa $o$ indirectamente, cuya venta se pretende gravar. La enajenación directa no presenta este nivel de dificultad para la Administración Tributaria.

Finalmente, luego de la dación de la Ley 29663, que por primera vez reguló en el Perú a las enajenaciones indirectas, se modificó hasta en tres oportunidades el régimen aplicable a este tipo de transacciones $y$, con ello, también a la norma de responsabilidad solidaria del ente emisor recogida en el artículo 68 de la LIR, aunque sin alterar el contenido esencial que hemos venido comentando a lo largo del presente trabajo. ${ }^{18}$

Dichas normas son las siguientes:

a) La Ley 29757, publicada el 21 de julio de 2011, que, entre otras disposiciones, estableció la no atribución de la responsabilidad solidaria cuando resulte aplicable la retención prevista en el inciso g) del artículo 71 de la LIR; esto es, cuando el adquirente en una enajenación indirecta es un sujeto domiciliado. ${ }^{19}$ Cabe resaltar que la Exposición de Motivos de esta norma sustentó la no atribución de responsabilidad en el hecho de que ya no habría necesidad de imputar la responsabilidad solidaria al emisor peruano, pues el adquirente domiciliado es agente de retención ${ }^{20}$, lo que fortalece lo comentado en la Sección I, en cuanto a que no hay razón alguna para que se mantenga dicha responsabilidad ahí cuando exista un adquirente peruano designado como agente de retención, lo que también ocurre en el caso previsto en el inciso c) del referido artículo 71 de la LIR.

b) La Ley 30050, Ley de Promoción del Mercado de Valores que, entre otras disposiciones, establece que la responsabilidad solidaria del ente emisor se mantiene aún en el caso de que la retención sea realizada por instituciones de compensación y liquidación de valores, esto es, para transacciones que ejecutadas a través de un mecanismo centralizado de negociación, como la Bolsa de Valores de Lima.

c) El Decreto Legislativo 1424, publicado el 13 de setiembre de 2018 que, en cuanto a la responsabilidad solidaria del emisor, regula el caso de la sucursal peruana de la entidad no domiciliada enajenante.

\section{PRECEDENTES ADMINISTRATIVOS APLICA- BLES AL CASO DEL ARTÍCULO 68 DE LA LIR}

\section{Informe $\mathrm{N}^{\circ}$ 173-2013-SUNAT/4B0000..$^{21,22}$}

En este informe, la Administración Tributaria con-

18. Que es contenido esencial.

19. Esta retención también fue incorporada por la Ley 29757.

20. Así, la Exposición de Motivos de la Ley 29757 señala lo siguiente:

c) Propuesta

(...)

“Cabe precisar que en los casos que -en aplicación del incorporado inciso g) del artículo $71^{\circ}$ de la LIR-el adquirente sea designado agente de retención del Impuesto a la Renta que grava la enajenación indirecta; ya no es necesario seguir imputando responsabilidad solidaria por dicho tributo, a la persona jurídica domiciliada en el país emisora de las acciones y participaciones representativas del capital materia de la referida enajenación."

Proyecto de Ley N²713/2010-PE, de fecha 9 de marzo de 2011, página 12.

21. Informe de la Administración Tributaria de fecha 18 de noviembre de 2013.

22. Los informes emitidos por la Administración Tributaria son vinculantes para los órganos de entidad, de acuerdo con lo dispuesto por el artículo 94 del Código Tributario. 
cluye que para efecto de lo dispuesto en el artículo 68 de la LIR, es posible determinar y exigir el pago de la deuda tributaria a la sociedad peruana emisora, como responsable solidaria, sin que previamente se hayan agotado las acciones para cobrar la misma al sujeto no domiciliado enajenante de tales valores mobiliarios.

A nuestro juicio, la posición de la Superintendencia Nacional de Aduanas y de Administración Tributaria - SUNAT antes descrita podría encontrar su sustento en la definición doctrinaria de responsabilidad solidaria, pues, como sostiene Villegas, hay solidaridad tributaria cuando dos o más sujetos quedan obligados al cumplimiento total de la misma prestación. A ello el citado autor agrega que "los vínculos son autónomos porque el fisco puede exigir indistintamente a cada uno la totalidad de la deuda, pero integran una sola relación jurídica por identidad de objeto (ídem debitum), por lo cual son también interdependientes." ${ }^{23}$

Sin embargo, el razonamiento jurídico de la Administración Tributaria que la lleva a concluir lo anterior no es acertado, pues sustenta su posición en el numeral 1 artículo 20-A del Código Tributario, norma que regula los efectos de la responsabilidad solidaria y dispone lo siguiente:

"1. La deuda tributaria puede ser exigida total o parcialmente a cualquiera de los deudores tributarios o a todos ellos simultáneamente, salvo cuando se trate de multas en los casos de responsables solidarios que tengan la categoría de tales en virtud a lo señalado en el numeral 1. del artículo 17, los numerales 1.y 2. del artículo 18 y el artículo 19."

Decimos que dicho razonamiento no es acertado, porque el referido artículo 20-A, introducido en el Código Tributario por el Decreto
Legislativo $981^{24}$, solo regula los efectos de la responsabilidad solidaria para el caso de las responsabilidades previstas en el citado Código y no para aquellas previstas por otras leyes, como es el caso del artículo 68 de la LIR; norma que, como hemos visto, califica como responsable solidario al emisor bajo un cuestionable criterio de conexión como es el de vinculación económica con el accionista, sin incluir parámetros razonables de limitación de los recursos con los que dicho emisor debiera responder por el impuesto a la ganancia de capital que grava la enajenación directa de acciones en Perú, como sí lo hacía el antecedente normativo recogido en el derogado inciso i) del artículo 67 de la LIR y el artículo 39 de su Reglamento.

En efecto, como surge del texto del precitado artículo 20-A, así como de la Exposición de Motivos del Decreto Legislativo $981^{25}$, el propósito de dicha norma es regular los supuestos de responsabilidad solidaria previstos en los artículos 16, 17, 18 y 19 del Código Tributario, referidos, respectivamente, al caso de los responsables solidarios de los representantes, de los adquirentes del activo o pasivo de la persona jurídi$\mathrm{ca}$, de otros sujetos entre los cuales figuran los agentes de retención - sin hacer mención alguna al caso de las sociedades emisoras-, y de los responsables por hecho generador.

Consideramos que atribuir los efectos de la responsabilidad solidaria prevista en el artículo 20-A del Código Tributario al emisor de las acciones como resultado de la aplicación del artículo 68 de la LIR como lo hace la SUNAT, no solo es equivocado desde un punto de vista técnico, sino también contrario a ley.

\section{Jurisprudencia del Tribunal Fiscal.}

De nuestra revisión de los precedentes del Tri-

23. Héctor Belisario Villegas, Curso de finanzas, derecho financiero y tributario (Buenos Aires: Editorial Astrea, 2016).

24. Decreto Legislativo 981 publicado el 15 de marzo de 2007.

25. Exposición de Motivos del Decreto Legislativo 981, páginas 1 a 3. 
bunal Fiscal, vemos que, a la fecha, no existe un desarrollo jurisprudencial significativo relacionado a controversias tributarias que involucren a los emisores de acciones como responsables solidarios en casos de enajenaciones efectuadas por sujetos no domiciliados.

Dos resoluciones que hemos identificado tratan acerca de controversias referidas al valor de mercado de las acciones transferidas entre partes no vinculadas, en las que el enajenante es un sujeto no domiciliado y el punto controvertido se refiere al valor de participación patrimonial que, para propósitos fiscales, debe tomarse en cuenta en la transacción.

Ese es el caso de las Resoluciones del Tribunal Fiscal No 03919-1-201726 y 00842-1-2018. ${ }^{27}$ Un criterio interesante que surge de la primera de ellas, pero que no está relacionado a la definición del alcance del artículo 68 en cuestión, es el parámetro utilizado para considerar vinculado al accionista, dado que en el ejercicio fiscal objeto de controversia la norma especial sobre vinculación para casos de enajenación de acciones no estaba vigente, y el Tribunal utiliza el criterio general previsto en el artículo 24 del Reglamento de la LIR, incorporado originalmente para efectos de la aplicación de las normas de precios de transferencia; las cuales, entre otros supuestos, consideraban vinculado a quien participara en más del 30\% del capital de una entidad. Posteriormente, se publicó y entró en vigor la norma reglamentaria sobre vinculación para el caso del artículo 68 de la LIR —artículo 39-F del Reglamento- que reducía el umbral del capital a $10 \%$, incrementando la base de emisores que puede ser considerado responsable solidario, así como también los costos de transacción que enfrentan las operaciones de venta directa de acciones peruanas. ${ }^{28}$

En el caso de la segunda resolución, se confirmó la interpretación acerca de la vinculación para aplicar el artículo 68 de la LIR en base al artículo 24 del Reglamento de la LIR mientras no existiera una norma reglamentaria que dotara de contenido a la vinculación exigida por la norma de responsabilidad solidaria, tal como se observa a continuación:

\begin{abstract}
"(...) Que en cuanto al cuestionamiento de la vigencia de la citada norma reglamentaria, en el sentido que no resulta aplicable al caso de autos, sino el artículo 39-F del citado reglamento, incorporado mediante Decreto Supremo $N^{\circ}$ 265-2013-EF, cabe señalar que el artículo 68 aplicable al caso de autos, fue incorporado por el artículo 6 de la Ley 29663, publicada el 15 de febrero de 2011, por lo que de conformidad con lo dispuesto por el artículo 109 de la Constitución Política del Perú, su aplicación es obligatoria desde el día siguiente de su publicación.
\end{abstract}

Que si bien el citado artículo 68 dispone que el reglamento señalará los supuestos en los que se configura la vinculación en el control, la administración o el capital, para efectos de determinar la responsabilidad solidaria de la persona jurídica domiciliada en el país emisora de los valores mobiliarios tratándose de

26. Resolución de fecha 5 de mayo de 2017.

27. Resolución de fecha 31 de enero de 2018.

28. Sobre este tema en particular, con la dación de esta norma reglamentaria en el año 2013, Silvia Muñoz tuvo los siguientes comentarios con los cuales coincidimos: "(...) El cambio además de resultar nocivo para las sociedades peruanas, enfrenta un cuestionamiento de fondo. De la exposición de motivos que sustenta este Decreto, pareciera que el objetivo era ampliar la responsabilidad tributaria de los emisores locales tratándose de las enajenaciones indirectas. Sin embargo, el decreto abarca no solo a esas transacciones, sino también a las directas. Esta norma debe revisarse, ya que puede generar severas consecuencias negativas en operaciones efectuadas por accionistas que no dominan societariamente una empresa y sobre las que, sin duda, no hay control alguno."

Gestión, "Responsabilidad tributaria en la enajenación de acciones", 22 de noviembre de 2013, acceso el 9 de julio de 2021, https://gestion.pe/impresa/responsabilidad-tributaria-enajenacion-acciones-53487-noticia/?outputType=amp 
enajenación directa de acciones efectuada por sujetos no domiciliados, a la fecha de su entrada en vigencia, ya se encontraba vigente el referido artículo 24 del Reglamento de la Ley del Impuesto a la Renta-sustituido por el artículo 2 del Decreto Supremo No 190-2005EF, publicado el 31 de diciembre de 2005 -el cual no hace distinción alguna en cuanto a su ámbito de aplicación -como sí lo hacía la norma original-, pues regula "para efectos de lo dispuesto en la Ley" los supuestos de partes vinculadas en función a su participación en el control, la administración o el capital.

Que siendo así, la mención del artículo 68 de la citada ley respecto de que el reglamento señalará los supuestos en los que se configura la referida vinculación, no enerva de modo alguno la aplicación inmediata de dicha norma legal, toda vez que a la fecha de inicio de su vigencia ya existía una norma reglamentaria que regulaba los mismos supuestos legales de vinculación por participación en el control, la administración o el capital."29

Consideramos pertinente resaltar un pronunciamiento adicional del Tribunal Fiscal que no trata directamente el supuesto de responsabilidad solidaria de la sociedad emisora previsto para enajenaciones directas en el artículo 68 de la LIR, pero del cual se podría inferir que cuando el adquirente es un sujeto domiciliado no resulta de aplicación la referida responsabilidad, al ser el comprador un agente de retención del impuesto y, como tal, se rige por otro tipo de responsabilidad solidaria. Este es el caso de la Resolución del Tribunal Fiscal Nº 04801-11$2019^{30}$, en la que se discute si el ajuste de valor de mercado entre partes no relacionadas debió ser parte del monto de la retención aplicada por el adquirente domiciliado, sin hacer referencia alguna a la responsabilidad del emisor.

De los hechos indicados en dicha resolución, se observa que los dos accionistas domiciliados en Chile, uno con el $8.17 \%$ de la sociedad emisora peruana, y el otro con el $76.83 \%$, transfirieron entre ambos el $42.5 \%$ de su participación en una compañía peruana ${ }^{31}$, con lo cual, no cabría duda de que, bajo una interpretación literal del artículo 68 bajo comentario, dicha sociedad calificaba como responsable solidario del impuesto a la ganancia de capital, dada la vinculación existente con el segundo accionista. Ello implícitamente confirmaría la posición comentada en la Sección I del presente trabajo, en el sentido de que no se configura la responsabilidad solidaria del emisor, cuando el adquirente en una enajenación directa de acciones es domiciliado y, como resultado, califica como agente de retención y responsable del referido impuesto. ${ }^{32}$

La citada Resolución del Tribunal Fiscal concluye lo siguiente:

“Que por tanto, atendiendo al concepto de
retención y que la puesta a disposición de los
vendedores de los importes de la venta de las
acciones fueron equivalentes a la diferencia
del precio de venta pactado en los contratos
y su costo computable, y que la posibilidad de
contacto directo con dicha suma permitió a
la recurrente realizar el descuento respectivo
por concepto de retención, lo que no podía
efectuarse con la diferencia generada por el
ajuste a valor de mercado determinado por
la Administración, conforme a lo dispuesto
por el artículo $2^{\circ}$ del Código Tributario (...) en
concordancia con el artículo $76^{\circ}$ de la Ley del

29. Página 14 de la Resolución del Tribunal Fiscal Nº 00842-1-2018.

30. Resolución publicada el 24 de mayo de 2019.

31. Ver página 2 de la Resolución comentada.

32. Sin perjuicio de ello, creemos que también podría interpretarse que, como quiera que la SUNAT acotó al adquirente como agente de retención, no era parte de la materia controvertida establecer la responsabilidad solidaria del ente emisor. 
Impuesto a la Renta, se establece que no se configuró la obligación tributaria de retener el Impuesto a la Renta respecto de la diferencia generada por el ajuste a valor de mercado, por lo que tampoco puede exigirse el pago de las retenciones a la recurrente. (...)" $)^{\prime 3}$

Dado el limitado desarrollo jurisprudencial existente con respecto al artículo 68 de la LIR, creemos que el Tribunal Fiscal tiene una buena oportunidad para, en el futuro, delinear sus alcances, de manera que se privilegie la seguridad jurídica y la reducción de los costos de transacción en los que incurren las partes - vendedor y comprador- en las enajenaciones directas de acciones, en lugar del mero fin recaudatorio, pues este último responde a una necesidad de corto plazo, mientras que el otro genera predictibilidad y atracción de inversión a corto, mediano y largo plazo. Algunos aspectos que podrían ser materia de pronunciamiento por parte de dicho Tribunal abarcan desde el cómputo de plazos de prescripción para el responsable solidario respecto de la deuda generada por el enajenante - el impuesto a la ganancia de capital por la venta de acciones-, hasta los límites de la responsabilidad y su potencial contravención al principio de no confiscatoriedad.

\section{REFLEXIONES FINALES}

a) A nuestro criterio, en un caso como el del artículo 68 de la LIR, la responsabilidad solidaria del ente emisor se fundamenta en la conexión con el contribuyente - vendedor o enajenante-; sin embargo, esta conexión debiera ser directa y proporcional, lo que a nuestro juicio en el caso analizado presenta deficiencias, debido a que:

(i) La sociedad emisora no es parte de la relación contractual que da origen al nacimiento de la obligación tributaria;

(ii) El vendedor, además, puede perder la conexión elegida por el legislador para atribuir responsabilidad solida- ria - vinculación a través del capital, la administración o el control con el emisor-al momento de transferir sus acciones a un tercero; $y$

(iii) Dada la redacción actual de la norma, se podría afirmar que la deuda tributaria por el impuesto a la ganancia de capital derivada de dicha transferencia podría ser exigida total o parcialmente al ente emisor $y$, en este escenario, dicho sujeto tendría que responder con sus propios recursos, sin límite, ante de falta de parámetros regulados.

b) Si se interpretara que el criterio de conexión emisor-vendedor es el adecuado, deberían establecerse límites a la responsabilidad solidaria del emisor, como los previstos en el derogado inciso i) del artículo 67 de la LIR y en su norma reglamentaria, los cuales se referían a dividendos y a créditos a favor del accionista enajenante. La finalidad recaudatoria no debería ser la exclusiva justificación de la responsabilidad establecida en el artículo 68 de la LIR.

c) No es razonable, necesario, ni conceptualmente acertado que coexistan dos tipos de responsabilidad solidaria sobre sujetos distintos - adquirente y emisor - en el caso de la enajenación directa. Una correcta interpretación del artículo 68 de la LIR debiera conducir a limitar la responsabilidad de la entidad emisora únicamente para supuestos en los que el adquirente sea un sujeto no domiciliado.

d) El propósito - ratio legis - de las normas con rango de ley que establecieron a las enajenaciones indirectas como transacciones potencialmente sujetas a imposición en el Perú, no fue regular la responsabilidad solidaria del ente emisor en el caso de ventas directas, lo que constituye una razón adicional para que su legalidad sea revisada. 
e) Atribuir los efectos de la responsabilidad solidaria prevista en el artículo 20-A del Código Tributario al emisor de las acciones como resultado de la aplicación del artículo 68 de la LIR como lo hace la Administración Tributaria, no solo es equivocado desde un punto de vista técnico, sino también contrario a ley.

f) Considerando el limitado desarrollo juris- prudencial existente con respecto al artículo 68 de la LIR, creemos que el Tribunal Fiscal tiene una oportunidad para que, en el futuro, establecer los alcances de la responsabilidad solidaria del emisor, privilegiando la seguridad jurídica y la reducción de los costos de transacción en los que incurren las partes - vendedor y comprador- en las enajenaciones directas de acciones, en lugar del propósito recaudatorio. 